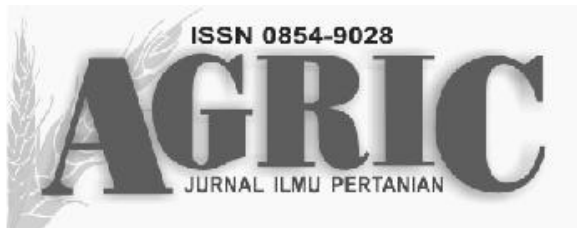

Fakultas Pertanian dan Bisnis Universitas Kristen Satya Wacana Jl. Diponegoro 52-60 SALATIGA 50711 - Telp. 0298-321212 ext 354

email: agric_fpb@yahoo.co.id, website: ejournal.uksw.edu/agric

\title{
KARAKTER AGRONOMI GENOTIPE GANDUM (Triticum Aestivum L.) PADA LAHAN TROPIS DATARAN RENDAH DI INDONESIA
}

\section{AGRONOMIC TRAITS OF WHEAT (Triticum Aestivum L.) GENOTYPES IN TROPICAL LOWLAND IN INDONESIA}

\section{Theresa Dwi Kurnia}

Fakultas Pertanian dan Bisnis

Universitas Kristen Satya Wacana

dwi.kurnia@staff.uksw.edu

\section{Nugraheni Widyawati}

Fakultas Pertanian dan Bisnis

Universitas Kristen Satya Wacana

\section{Djoko Murdono}

Fakultas Pertanian dan Bisnis

Universitas Kristen Satya Wacana

\section{Endang Pudjihartati}

Fakultas Pertanian dan Bisnis

Universitas Kristen Satya Wacana

Diterima 25 November 2016, disetujui 6 Desember 2016

\begin{abstract}
Development of tropical wheat that suitable to low altitude is important in Indonesia. Aims of the research was to determine agronomic traits and select of wheat genotypes adaptive to tropical lowland. Three years study was conducted by planting ten wheat genotypes in Tlogoweru village, Guntur Subdistrict, Demak, Central Java at the altitude \pm 20 meters above sea level, from 2013 to 2015. From ten wheat genotypes planted in 2013, five wheat genotypes were considered adaptive, i.e., ALTAR, BASRIBEY, LAJ3302, OASIS and SELAYAR. In 2014 four genotypes were selected, they are ALTAR, BASRIBEY, LAJ3302 and OASIS. Finnaly, in 2015 genotype ALTAR was prominent candidate for the lowland tropical wheat varieties in study site. Among genotypes ALTAR had highest plant height, seed weight per panicle, number of seeds per panicle, number of productive tillers and yield estimates.
\end{abstract}

Keywords: Adaptation, heat stress, lowland, tropical wheat, agronomic traits 


\section{PENDAHULUAN}

Kebutuhan bahan pangan dari biji gandum di dunia terus meningkat setiap tahunnya, termasuk kebutuhan gandum di Indonesia. Selama ini penelitian untuk pengembangan gandum di Indonesia lebih terfokus pada wilayah dataran tinggi seperti di Lembang-Jawa Barat, di MalinoSulawesi Selatan, di Wonosobo, Salatiga dan Umbul Sidomukti-Jawa Tengah dimana semua wilayah tersebut berada lebih dari 400 meter dpl atau tergolong ke dalam dataran tinggi. Kendala yang dihadapi dalam pengembangan gandum tersebut adalah persaingan dengan komoditas lain yang sudah ditanam petani sebelumnya serta minimnya pengetahuan mengenai budidaya gandum.

Untuk mengatasi tantangan tersebut, kegiatan pengembangan gandum kini mulai mengarah pada pengembangan gandum tropis dataran rendah dimana masih terdapat lahan yang dapat dimanfaatkan. Namun demikian, terdapat beberapa permasalahan yang dihadapi, seperti belum adanya varietas gandum untuk wilayah tropis dataran rendah serta rentannya wilayah tersebut terhadap cekaman suhu tinggi dan kekeringan (Guendouz et al., 2012; Shefazadeh et al., 2012). Beberapa peneliti mencoba pengujian gandum dataran rendah melalui introduksi genotipe baru dari luar negeri yang memiliki sifat ketahanan tersebut (Wahyu et al., 2013). Batan melakukan penyinaran untuk mendapatkan mutasi gen dengan sifat ketahanan cekaman suhu tinggi atau kekeringan. Penyinaran dengan sinar gamma juga dilakukan untuk meningkatkan keragaman genetik gandum sehingga diperoleh genotipe yang dapat ditanam pada dataran rendah (Riyati, 2012) serta diperoleh mutan putatif yang toleran suhu tinggi (Setiawan et al., 2015). Peneliti lain melakukan uji adaptasi pada beberapa genotipe gandum dengan harapan ditemukannya tetua yang adaptif di dataran rendah (Puspita et al., 2013).
Salah satu faktor penghambat tumbuh tanaman adalah air, dimana keterbatasan air pada saat penanaman akan sangat mempengaruhi kondisi fisiologis tanaman, seperti terhambatnya proses penyerapan unsur hara dan translokasi hasil fotosintesis ke seluruh tubuh tanaman termasuk proses pengisian biji (Wahyu et al., 2013). Begitu juga dengan suhu tinggi yang dapat berakibat pada rendahnya nilai produksi tanaman gandum (Ashari et al., 2012; Asseng et al., 2010). Untuk itu perlu dilakukan kegiatan adaptasi dari beberapa genotipe gandum yang telah ada hingga diperoleh calon varietas gandum tropis dataran rendah. Penelitian ini bertujuan untuk melakukan evaluasi dan seleksi genotipe gandum adaptif pada lahan tropis dataran rendah berdasarkan karakter agronomi dari beberapa genotipe gandum yang diuji.

\section{METODE PENELITIAN}

Penelitian dilaksanakan dalam tiga tahap dengan waktu yang berbeda di Desa Tlogoweru, Kecamatan Guntur, Demak dengan ketinggian tempat \pm 20 meter dpl. Penelitian pertama dilaksanakan pada tahun 2013, penelitian kedua pada tahun 2014 dan penelitian ketiga pada tahun 2015, masing-masing dilaksanakan antara bulan April-Agustus. Ketiga tahap penelitian tersebut disusun dengan Rancangan Acak Kelompok. Untuk mengetahui perbedaan antar genotipe dilakukan uji Beda Nyata Jujur pada taraf kepercayaan $95 \%$. Materi genetik yang digunakan pada penelitian tahap pertama terdiri dari sepuluh genotipe, tahap kedua lima genotipe dan tahap ketiga empat genotipe. Penanaman setiap genotipe dilakukan pada petak dengan ukuran 5 $\mathrm{m} \times 1.5 \mathrm{~m}$, jarak antar petak $0.5 \mathrm{~m}$ dan dalam petak dibuat 6 baris, jarak tanam dalam baris 5 $\mathrm{cm}$, jarak tanam antar baris $25 \mathrm{~cm}$. Pemupukan menggunakan pupuk kotoran sapi yang telah matang, dilakukan dalam 2 tahap dengan dosis total 10 ton/ha. Pemupukan pertama diberikan bersamaan dengan waktu tanam dan pemupukan 
berikutnya dilakukan 10 hari setelah tanam. Penyiraman secara intensif dilakukan pada tahap awal penanaman hingga benih berkecambah, tanah dijaga agar tetap lembab. Penyiraman selanjutnya dilakukan hanya sekali dalam satu minggu. Pemanenan dilakukan saat tanaman gandum telah tua, ditandai dengan malai yang membengkok. Panen dilakukan secara manual dengan memangkas tanaman hingga pangkal batang, selanjutnya dilakukan penjemuran hingga benih kering.

Dalam penelitian ini penurunan jumlah genotipe yang ditanam merupakan hasil seleksi secara alami terhadap genotipe yang tidak mampu bertahan hidup hingga akhir periode penanaman atau berproduksi sangat rendah. Hasil penanaman selama tiga tahun akan dibandingkan untuk mengetahui kemampuan produksi. Untuk mendukung pengamatan utama, dilakukan pengamatan selintas mengenai iklim dan tanah pada lokasi penelitian. Parameter utama yang diamati adalah tinggi tanaman, jumlah anakan, berat biji per malai, jumlah biji per malai dan berat 1000 benih serta estimasi produksi yang dilanjutkan dengan perhitungan Stress Susceptibility Index (SSI) atau Indeks Sensitivitas Cekaman (ISC) (Widyawati et al., 2015). ISC = (1-Y/Yp) : (1$\mathrm{X} / \mathrm{Xp})$

Dimana:

Y : Rata-rata hasil pada kondisi tercekam

Yp : Rata-rata hasil pada kondisi tidak tercekam

$\mathrm{X}$ : Rata-rata hasil semua genotipe pada kondisi tercekam

Xp : Rata-rata hasil semua genotipe pada kondisi tidak tercekam
Nilai ISC $<0.5$ menunjukkan ketahanan terhadap cekaman; ISC > $0.5<1$ menunjukkan ketahanan medium; ISC $>1$ menunjukkan tidak tahan terhadap cekaman. Nilai Yp diperoleh dari produksi rata-rata deskripsi varietas gandum Dewata.

\section{HASIL DAN PEMBAHASAN}

Berdasarkan penelitian yang telah dilakukan pada sepuluh genotipe gandum tahun 2013, terseleksi secara alami lima genotipe gandum yang akan diadaptasikan kembali pada tahun 2014, yaitu ALTAR, BASRIBEY, LAJ3302, OASIS dan SELAYAR. Begitu juga pada tahun 2015 hanya empat genotipe yang dilanjutkan, yaitu ALTAR, BASRIBEY, LAJ3302 dan OASIS. Genotipe lain yang tidak dilanjutkan dianggap tidak mampu menjadi calon varietas dataran rendah tropis karena biji yang dihasilkan sangat rendah sehingga tidak dapat ditanam pada tahun berikutnya.

\section{Iklim dan Tanah}

Lahan tempat penanaman gandum memiliki jenis tanah grumosol (Demak dalam angka, 2014), dimana kondisi jenis lahan tersebut memiliki struktur tanah padat dan keras terutama pada musim kemarau, tanah akan semakin keras dan retak-retak. Selama tiga tahun pengujian, lokasi penanaman gandum dilakukan pada lahan yang sama. Analisis tekstur tanah yang dilakukan juga menunjukkan bahwa lokasi penelitian memiliki tekstur liat, memiliki sifat yang sama dengan jenis tanah grumosol. Data kesuburan tanah selama periode penanaman dapat dilihat pada Tabel 1 , sedangkan suhu dan curah hujan dapat dilihat pada Tabel 2.

Tabel 1 Data analisis tanah lokasi penelitian tahun 2013

\begin{tabular}{cccccc}
\hline \multirow{2}{*}{ Hara } & $\mathrm{pH}$ & $\mathrm{BO}$ & $\mathrm{N}$ & $\mathrm{P}$ & $\mathrm{K}$ \\
\cline { 2 - 6 } & $\mathrm{H}_{2} \mathrm{O}=7.6$ & \multirow{2}{*}{$1.29 \%$} & $1.78 \%$ & $1.75 \%$ & $0.71 \%$ \\
\hline \multirow{2}{*}{ Tekstur } & & & Pasir & Debu & Liat \\
\cline { 4 - 6 } & & & $4.40 \%$ & $38.24 \%$ & $57.36 \%$ \\
\hline
\end{tabular}


Tabel 2 Data suhu dan curah hujan pada lokasi penanaman gandum di Demak

\begin{tabular}{lccccccccc}
\hline \multirow{2}{*}{ Bulan } & \multicolumn{3}{c}{$\mathrm{T}$ Maks $\left({ }^{\circ} \mathrm{C}\right)$} & \multicolumn{3}{c}{$\mathrm{T}$ Min $\left({ }^{\circ} \mathrm{C}\right)$} & \multicolumn{3}{c}{ Curah Hujan $(\mathrm{mm})$} \\
\cline { 2 - 11 } & $2013^{*}$ & 2014 & 2015 & $2013^{*}$ & 2014 & 2015 & $2013^{*}$ & 2014 & 2015 \\
\hline April & 35.4 & 34.7 & 35.3 & 24.2 & 25.3 & 23.5 & 2.3 & 4.4 & 6.1 \\
Mei & 36.2 & 34.8 & 36.3 & 25.4 & 26.6 & 23.8 & 0 & 3.9 & 2.3 \\
Juni & 36.5 & 36.2 & 36.7 & 25.2 & 26.2 & 23.3 & 0 & 1.1 & 0 \\
Juli & 38.1 & 35.0 & 38.0 & 25.3 & 25.8 & 33.4 & 0 & 2.5 & 0 \\
Agustus & 37.5 & 33.4 & 38.0 & 25.1 & 25.3 & 22.6 & 0 & 4.7 & 0 \\
September & 38.2 & 36.4 & 39.7 & 24.5 & 24.4 & 23.1 & 0.5 & 0.8 & 0 \\
\hline \multicolumn{1}{c}{ Rerata } & 36.98 & 35.08 & 37.33 & 24.95 & 25.6 & 24.95 & 0.47 & 2.9 & 1.4 \\
\hline
\end{tabular}

*Sumber: Kantor Penyuluhan Pertanian Desa Telogoweru, Kec. Guntur, Kab. Demak

\section{Karakter Tinggi Tanaman}

Tinggi tanaman merupakan salah satu karakter yang paling berpengaruh pada indeks derajat toleransi terhadap cekaman suhu tinggi dan kekeringan sehingga dapat digunakan sebagai salah satu kriteria pemilihan (Jeffrey dan Reynolds, 2001; Zahoor et al., 2014). Pada Tabel 3 dapat dilihat bahwa tinggi tanaman tahun 2014 mengalami peningkatan dibandingkan pada tahun 2013 untuk semua genotipe. Hal ini menunjukkan adanya peningkatan kemampuan tumbuh tanaman yang terjadi pada kelima genotipe tersebut. Sedangkan pada tahun 2015, empat genotipe yang dicoba mengalami penurunan tinggi tanaman dibandingkan tahun sebelumnya.

Pertumbuhan tinggi tanaman secara umum dipengaruhi oleh aktivitas auksin yang terdapat di titik tumbuh apikal yaitu dengan memacu pembelahan sel. Aktivitas auksin sangat dipengaruhi suhu sehingga pada kondisi suhu yang sangat tinggi akan menghambat kerja auksin dalam memacu tinggi tanaman (Wahid et al., 2007), dimana pada suhu tinggi auksin menjadi tidak aktif. Dari keempat genotipe yang diuji pada tahun 2015 terlihat bahwa genotipe ALTAR mampu menunjukkan tinggi tanaman tertinggi dibandingkan ketiga genotipe lainnya. Hal tersebut dapat menunjukkan bahwa secara fisiologis genotipe ALTAR sudah mampu beradaptasi pada lingkungan dengan cekaman suhu tinggi.

\section{Karakter Jumlah Anakan Produktif}

Berdasarkan pengujian yang dilakukan, semua genotipe yang diuji mengalami peningkatan jumlah anakan produktif (Tabel 3). Pada tahun 2013 jumlah anakan tertinggi hanya mencapai 3.26 dengan rata-rata $1.59 \pm 0.84$. Pengujian tahun 2014 terjadi peningkatan jumlah anakan pada semua genotipe yang ditanam tetapi pada tahun 2015 genotipe LAJ3302 dan OASIS mengalami penurunan jumlah anakan. Pada pengujian tahun 2015, genotipe ALTAR mengalami peningkatan dan merupakan genotipe dengan jumlah anakan produktif tertinggi dibandingkan dengan genotipe lain yang diuji. Hal ini menunjukkan terjadi peningkatan kemampuan tumbuh pada genotipe ALTAR meskipun ditanam pada kondisi kurang optimal bagi penanaman gandum.

Hasil produksi tanaman gandum sangat dipengaruhi oleh jumlah anakan produktif yang terbentuk (Lee dan Herbek, 2009). Pada umumnya tanaman gandum yang terpapar cekaman suhu tinggi atau kekeringan akan mengalami pemendekan fase vegetatif, diantaranya tidak terbentuknya anakan, hal ini dapat menyebabkan jumlah anakan yang terbentuk sangat rendah (Biesaga et al., 2014). Seperti pada penelitian ini dimana penanaman 
Tabel 3 Tinggi tanaman dan jumlah anakan produktif beberapa genotipe gandum

\begin{tabular}{lcccccc}
\hline \multirow{2}{*}{ Genotipe } & \multicolumn{3}{c}{ Tinggi Tanaman $(\mathrm{cm})$} & \multicolumn{3}{c}{ Jumlah Anakan } \\
\cline { 2 - 7 } & 2013 & 2014 & 2015 & 2013 & 2014 & 2015 \\
\hline ALTAR & 18.75 & 49.27 & $47.67^{*}$ & 2.1 & 6.15 & $7.81^{*}$ \\
BASRIBEY & 16.99 & 38.28 & 42.17 & 1.26 & 4 & 3.74 \\
G-21 & 12.41 & - & - & 1.12 & - & - \\
H-21 & 18.13 & - & - & 0.48 & - & - \\
HP1744 & 16.11 & - & - & 1.27 & - & - \\
LAJ3302 & 18.31 & $51.39^{*}$ & 40.39 & 3.26 & 7.3 & 4.65 \\
MENEMEN & 12.64 & - & - & 0.88 & - & - \\
OASIS & 17.33 & 48.02 & 34.84 & 2.46 & 5.9 & 4.52 \\
RABE/2*MO88 & 14.17 & - & - & 1.1 & - & - \\
SELAYAR & 17.67 & 48.95 & - & 1.96 & 6.2 & - \\
\hline \multicolumn{1}{c}{ Rerata } & $16.25 \pm 2.35$ & $47.18 \pm 5.13$ & $40.23 \pm 4.52$ & $1.59 \pm 0.84$ & $5.91 \pm 1.20$ & $4.30 \pm 0.49$ \\
\hline
\end{tabular}

Keterangan: $(-)=$ Tidak dilakukan penanaman; $(*)=$ Berbeda nyata

tahun 2015 sebagian besar genotipe mengalami penurunan jumlah anakan produktif disebabkan peningkatan suhu dibandingkan musim tanam tahun 2014.

\section{Karakter Berat Biji per Malai}

Berat biji per malai tanaman sangat dipengaruhi oleh proses pengisian biji. Pada tahap ini kebutuhan air akan sangat diperlukan untuk proses translokasi tanaman. Hasil penelitian menunjukkan bahwa terjadi penurunan berat biji per malai dari tahun ke tahun untuk semua genotipe yang dicoba (Gambar 1). Rendahnya curah hujan dan minimnya irigasi merupakan salah satu kendala yang dihadapi dalam proses budidaya gandum di dataran rendah tropis (Mohammadi, 2012). Diperlukan efisiensi transpirasi yang tinggi pada tanaman agar pada kondisi air yang terbatas tanaman tetap dapat melakukan aktivitas fisiologis (Changhai et al., 2010). Selain itu suhu yang terlalu tinggi dapat menjadi salah satu penyebab rendahnya produksi, dimana setiap aktivitas fisiologis dan biokimia di dalam tanaman akan sangat dipengaruhi suhu (Modhej et al., 2015). Pada penelitian yang telah dilakukan tahun 2015 memberikan hasil bahwa genotipe ALTAR memiliki berat biji per malai yang paling tinggi dibandingkan ketiga genotipe lainnya. Meskipun hasil tersebut tidak berbeda secara signifikan tetapi dibandingkan dengan nilai

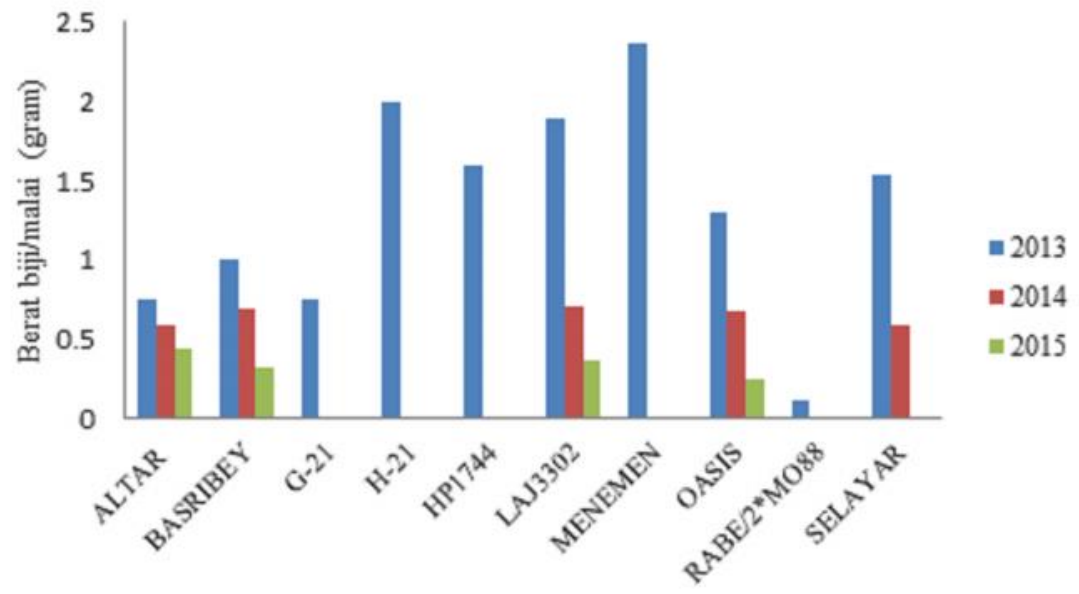

Gambar 1 Grafik berat biji per malai (gram) 
rata-rata pada tahun 2015, selisih ALTAR berada di atas nilai standar deviasi. Hal ini dapat menunjukkan bahwa genotipe ALTAR lebih mampu bertahan pada wilayah tropis dataran rendah.

\section{Karakter Jumlah Biji per Malai}

Kegiatan untuk deteksi ketahanan tanaman terhadap kekeringan dapat dilakukan pada tahap perkecambahan, tetapi untuk beberapa genotipe gandum yang diuji, nantinya diharapkan akan memberikan hasil biji yang telah mengalami proses adaptasi sehingga penanaman hingga panen sangat penting untuk dilakukan. Perhitungan hasil panen yang menunjukkan banyaknya biji yang mampu terbentuk dapat menggambarkan besarnya keberhasilan dalam proses penyerbukan. Umumnya pada wilayah dataran rendah tropis tanaman gandum mengalami cekaman suhu tinggi dan kekeringan. Hal ini dapat terlihat pada tingginya polong hampa yang disebabkan polen menjadi steril (Rasul et al., 2011). Tetapi pada hasil penelitian ini terlihat adanya peningkatan jumlah biji per malai pada tahun 2014 dibandingkan tahun 2013 (Gambar 2), yang menunjukkan genotipe gandum yang ditanam mampu beradaptasi dan telah mengalami kemajuan seleksi (Semenov et al., 2014). Pada penanaman tahun 2015, genotipe ALTAR memiliki jumlah biji per malai tertinggi sehingga dapat dikatakan bahwa genotipe ALTAR memiliki keberhasilan yang tinggi dalam hal penyerbukan dan pembentukan biji.

\section{Karakter Berat 1000 Biji}

Benih dengan berat 1000 biji yang tinggi menggambarkan kualitas benih yang baik dan umumnya memiliki daya berkecambah yang tinggi. Untuk itu pengamatan berat 1000 biji penting dilakukan dalam menilai kualitas benih (Protic et al., 2007). Berdasarkan uji yang telah dilakukan, terjadi peningkatan berat 1000 biji dari tahun ke tahun dimana hal ini menunjukkan bahwa terjadi peningkatan kualitas dari benih yang dihasilkan (Gambar 3). Pada penelitian tahun 2014 terlihat bahwa pada semua genotipe yang ditanam terjadi peningkatan dibandingkan tahun 2013. Pada tahun 2015 kembali mengalami penurunan berat 1000 biji dengan nilai tertinggi diperoleh pada genotipe OASIS. Nilai berat 1000 biji yang terjadi mulai masa antesis hingga masak fisiologis sangat dipengaruhi oleh proses pengisian biji atau translokasi pada tanaman. Proses translokasi tersebut salah satunya tergantung pada ketersediaan air oleh tanaman sehingga penurunan nilai berat 1000 biji tahun 2015 dapat disebabkan karena rendahnya curah hujan selama kegiatan penelitian berlangsung.

\section{Estimasi Produksi beberapa Genotipe Gandum}

Data estimasi hasil produksi beberapa genotipe gandum dihitung berdasarkan hasil per tanaman dikalikan dengan jumlah tanaman per hektar. Tabel 4 menunjukkan besarnya jumlah produksi

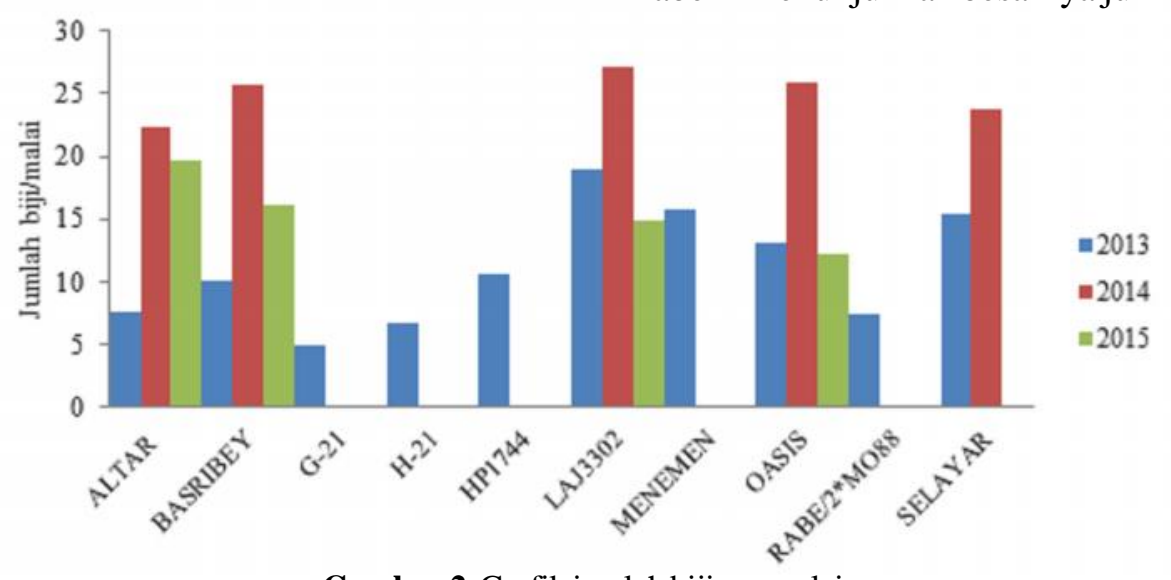

Gambar 2 Grafik jumlah biji per malai 
beberapa genotipe gandum yang ditanam selama tiga tahun dan nilai ISC. Pada percobaan tahun 2013 dan 2014 menunjukkan ketahanan cekaman tertinggi pada genotipe LAJ3302, hal ini juga nampak pada produksi tahun 2014 genotipe LAJ3302 memberikan hasil tertinggi. Pada percobaan tahun 2015 semua genotipe gandum yang ditanam mengalami penurunan hasil produksi, dengan penurunan terendah pada genotipe ALTAR dan genotipe ALTAR menunjukkan jumlah produksi tertinggi dibandingkan genotipe lain yang ditanam yaitu 2.71 ton per hektar. Didukung dengan data berat biji per malai, jumlah biji per malai dan berat 1000 biji tertinggi, akan mempengaruhi hasil produksi per hektar (Mohammadi, 2012). Nilai ISC $<0.5$ menun- jukkan genotipe tersebut memiliki ketahanan terhadap cekaman, hal ini dapat menjelaskan bahwa pada tahun 2015 genotipe ALTAR lebih mampu beradaptasi pada kondisi dengan cekaman kekeringan dan suhu tinggi atau lebih toleran dibandingkan genotipe lain yang ditanam (Bala et al., 2014).

Secara umum dapat dilihat bahwa estimasi produksi pada tahun 2014 mengalami peningkatan hasil pada semua genotipe tetapi pada tahun 2015 kembali mengalami penurunan. Hal ini dapat disebabkan karena adanya kemunduran sifat genetis dari benih yang dihasilkan sehingga sebaiknya benih gandum diberi perlakuan priming sebelum ditanam (Abnavi dan Gobadhi, 2012). Selain itu kemampuan produksi juga

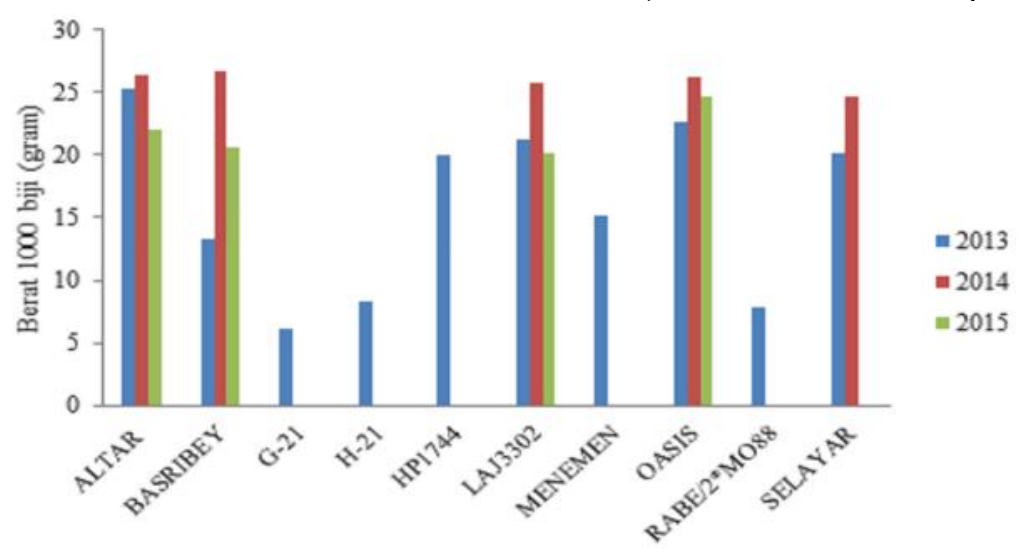

Gambar 3 Grafik berat 1000 biji (gram)

Tabel 4 Estimasi produksi per hektar beberapa genotipe gandum

\begin{tabular}{lcccccc}
\hline \multirow{2}{*}{ Genotipe } & \multicolumn{7}{c}{ Estimasi produksi (ton/ha) } \\
\cline { 2 - 7 } & 2013 & ISC & 2014 & ISC & 2015 & ISC \\
\hline ALTAR & 1.19 & 1.29 & 2.72 & 2.72 & $2.71 *$ & 0.16 \\
BASRIBEY & 0.94 & 1.47 & 2.06 & 10.06 & 0.90 & 1.31 \\
G-21 & 0.63 & 1.70 & - & & - & \\
H-21 & 0.72 & 1.64 & - & & - & \\
HP1744 & 1.52 & 1.05 & - & & - & \\
LAJ3302 & 4.62 & -1.21 & 3.83 & -9.68 & 1.07 & 1.20 \\
MENEMEN & 1.56 & 1.02 & - & & - & \\
OASIS & 2.39 & 0.42 & 3.00 & -0.44 & 0.86 & 1.33 \\
RABE/2*MO88 & 0.09 & 2.09 & - & & - & \\
SELAYAR & 2.25 & 0.52 & 2.73 & 2.54 & & \\
\hline
\end{tabular}

Keterangan: $(-)=$ Tidak dilakukan penanaman; $(*)=$ Berbeda nyata;

ISC $=$ Indeks Sesitivitas Cekaman 
dipengaruhi cuaca selama penanaman, pada tahun 2013 dan 2015 rerata suhu maksimal mencapai $36.98{ }^{\circ} \mathrm{C}$ dan $37.33{ }^{\circ} \mathrm{C}$ dimana suhu tersebut lebih tinggi dibandingkan rerata suhu maksimal pada tahun 2014 , yaitu $35.08{ }^{\circ} \mathrm{C}$

Data estimasi produksi pada penelitian ini apabila dibandingkan dengan varietas gandum nasional yaitu Dewata yang memilik potensi hasil 2.96 ton per hektar (Balitsereal, 2012) yang ditanam pada dataran tinggi ( $>400$ meter dpl), produksi genotipe ALTAR sudah cukup mendekati. Dan bila dibandingkan penanaman varietas Dewata pada dataran rendah ( $<200$ meter dpl), produksi genotipe ALTAR lebih tinggi (Zubaidi et al., 2014). Didukung dengan nilai rata-rata produksi beberapa genotipe gandum yang juga dilakukan pada wilayah dengan cekaman suhu tinggi dan kekeringan hanya mencapai 0.38 ton per hektar dan 0.42 ton per hektar (Zarei et al., 2013). Kemampuan adaptasi inilah yang menyebabkan genotipe ALTAR mampu memberikan hasil produksi yang cukup baik.

\section{KESIMPULAN}

Dari penanaman sepuluh genotipe pada tahun 2013, terseleksi lima genotipe gandum yang diadaptasikan kembali pada tahun 2014, yaitu ALTAR, BASRIBEY, LAJ3302, OASIS dan SELAYAR. Lalu pada tahun 2015 hanya empat genotipe yang dilanjutkan, yaitu ALTAR, BASRIBEY, LAJ33022 dan OASIS. Masingmasing genotipe memiliki karakter agronomi yang berbeda dengan hasil terbaik terlihat pada genotipe ALTAR karena berdasarkan pengamatan karakter tinggi tanaman, jumlah anakan produktif, berat biji per malai, jumlah biji per malai dan estimasi hasil per hektar mampu menghasilkan nilai tertinggi dibandingkan genotipe yang lain.

\section{UCAPAN TERIMAKASIH}

Peneliti mengucapkan terimakasih kepada Dikti yang telah membiayai penelitian ini melalui Hibah
Ungulan Perguruan Tinggi selama tiga tahun. Ucapan terimakasih juga kepada Rektor Universitas Kristen Satya Wacana (UKSW), Salatiga dan kepada Dekan Fakultas Pertanian dan Bisnis, UKSW.

\section{DAFTAR PUSTAKA}

Abnavi M.S., Ghobadi M. 2012. The effects of source of priming and post-priming storage duration on seed germination and seedling growth characteristics in wheat (Triticum aestivem L.). J. Agric Sci. 4 (9): 256-268.

Ashari S, B. Waluyo, I. Yulianah, N. Kendarini, M. Jusuf. 2012. Stability of wheat genotypes adapted in tropical medium and lowland. Agrivita J. 34 (1): 1-9.

Bala S., Asthir B., Bains N.S. 2014. Effect of terminal heat stress on yield and yield attributes of wheat. Indian. J. Applied. Res. 4 (6): 1-2.

Balitsereal. 2012. Varietas Dewata (Gandum). http://balitsereal.litbang.pertanian.go.id [21 Februari 2012].

Biesaga K.J., Ostrowska A., Filek M., Dziurka M., Waligórski P., Mirek M., Kościelniak J. 2014. Evaluation of spring wheat (20 varieties) adaptation to soil drought during seedlings growth stage. Agric J. 4: 96-112.

Changhai S., D. Baodi, Q. Yunzhou, L. Yuxin, S. Lei, L. Mengyu, Haipei. 2010. Physiological regulation of high transpiration efficiency in winter wheat under drought conditions. Plant Soil Environ. 56 (7): 340-347.

Demak Dalam Angka. 2014. http://demakkab. go.id/publikasi/demak-dalam-angka/ [14 April 2014].

Guendouz A., S. Guessoum, K. Maamri, M. Benidir, M. Hafsi. 2012. Canopy temperature efficiency as indicators for 
drought tolerance in durum wheat (Triticum Durum Desf.) in semi arid conditions. J. Agric. Sustainability. 1 (1): 23-38.

Jeffrey W.W., M.P. Reynolds. 2001. A physiological perspective on modeling temperature response in wheat and maize crops. Pp 8-17. In Jeffrey W. White (eds.) Proceedings of a Workshop, CIMMYT. Modeling Temperature Response in Wheat and Maize. El Batán, Mexico, 23-25 April 2001.

Lee C., J. Herbek. 2009. Growth and Development. Pp 6-12. In W. Bruening, J.D. Green, J. Grove, J.R. Martin, L. Murdock, G. Schwab, D.V. Sanford (eds.) Plant and Soil Sciences. AComprehensive Guide to Wheat Management in Kentucky.

Modhej A., R. Farhoudi, A. Afrous. 2015. Effect of post-anthesis heat stress on grain yield of barley, durum and bread wheat genotypes. J Scientific Res Dev. 2 (6): 127-131.

Mohammadi M. 2012. Effects of kernel weight and source-limitation on wheat grain yield under heat stress. African J. Biotechnol. 11 (12): 2931-2937.

Protic R, P. Jovin, N. Protic, S. Jankovic, Ž. Jovanovic. 2007. Mass of 1,000 grains in several winter wheat genotypes, at different dates of sowing and rates of nitrogen fertilizer. Romanian Agric. Res. 24: 39-42.

Puspita, Y.C., Widyawati, N., Murdono, D. 2013. Penampilan Pertumbuhan dan Hasil Dua Belas Genotipe Gandum Ditanam di Dataran Rendah dalam rangka Mencari Calon Tetua Adaptif Dataran Rendah. Agric Jurnal Ilmu Pertanian. 24 (2): 9-18.

Rasul G., Q.Z. Chaudhry, A. Mahmood, K.W. Hyder. 2011. Effect of temperature rise on crop growth and productivity. Pakistan J. Meteorology 8 (15): 53-62.
Riyati R. 2012. Perbaikan Adaptasi Tanaman Gandum (Triticum aestivum L.) di Dataran Rendah Melalui Mutasi Induksi. J. Biota. 17 (1)

Semenov M.A., P. Stratonovitch, F. Alghabari, M.J. Gooding. 2014. Adapting wheat in Europe for climate change. J. Cereal Sci. 59: 245-256.

Setiawan R.B., Khumaida N., Dinarti D. 2015. Induksi Mutasi Kalus Embriogenik Gandum (Triticum aestivum L.) melalui Iradiasi Sinar Gamma untuk Toleransi Suhu Tinggi. Jurnal Agronomi Indonesia 43 (1): 36-44.

Shefazadeh, M.K., M. Mohammadi, R. Karimizadeh, G. Mohammadinia. 2012. Tolerance study on bread wheat genotypes under heat stress. Ann. Biol Res. 3 (10): 4786-4789.

Wahid A., S. Gelani, M. Ashraf, M.R. Foolad. 2007. Heat tolerance in plants: An overview. Environ. Exp. Bot. 61: 199-223.

Wahyu Y., P.S. Aditya, G.B. Sri. 2013. Adaptabilitas genotipe gandum introduksi di dataran rendah. Buletin Agrohorti 1 (1): 1-6.

Widyawati N., T.D. Kurnia, D. Murdono. 2015. Dynamization performance of thrirteen wheat genotypes during three planting season for adaptation in tropical lowland. Agrivita J. 37 (2): 115-122.

Zahoor S.A., A. S, Altaf, M.G. Sughra, T.H. Tanveer. 2014. Evaluation and selection of bread wheat genotypes grown under different environments. Internat. Biotechnol. Color J. 4 (1): 8-14.

Zarei B.,A.Naderi, M.R.K Jalal, Sh. Lack,A.Modhej. 2013. Determination of physio-logical traits related to terminal drought and heat stress tolerance in spring wheat genotypes. J. Agric. Crop Sci. 5 (21): 2511-2520. 
Zubaidi A., Budianto V.F.A., Wiresyamsi A., Abdurrahman H. 2014. Growth and yield of wheat (Triticum aestivum) adapted to lowland Lombok Island as an alternative food crop for dryland. J. Degraded and Mining Lands Management. 2(1): 243-250.

$* * *$ 